\title{
Does Hepatitis C Treatment Adherence Affect Risk of Liver Transplantation? A Historical Cohort Study
}

\author{
Derek Ems, MPH; Patrick Racsa, MS; Chris Anderson, PharmD; Fran Gregory, PharmD; \\ Karen Worley, PhD; Joel V. Brill, MD; and Worthe Holt, MD
}

\begin{abstract}
BACKGROUND: Chronic hepatitis $\mathrm{C}$ virus (HCV) is the primary cause of liver failure leading to transplantation, and medication adherence is essential to the therapeutic efficacy of HCV treatments. While there is evidence linking poor adherence with increased utilization and cost, published literature lacks examination of the association between medication adherence and risk of liver transplant. In addition, the impact of HCV treatment on total costs of liver transplantation is not well documented.
\end{abstract}

OBJECTIVES: To compare (a) the relative risk of liver transplant by adherence in patients treated for HCV and (b) the total health care costs in treated and untreated patients who require liver transplant.

METHODS: This observational, historical cohort study was conducted using administrative data from the Humana Research Database. To be included, patients were required to have a documented HCV diagnosis or treatment between January 1,2008 , and June 30,2013 . Patients were excluded if they had a hepatitis B diagnosis, were not fully insured by a commercial or Medicare Advantage Prescription Drug plan, or were outside the age range of 19-89 years. No minimum pre- or post-index enrollment period was required, and patients were followed for their entire post-index enrollment through December 31, 2013. The study population was divided into treated and untreated groups and then subdivided by presence or absence of a liver transplant. Date of liver transplant was defined as the index date for untreated liver transplant patients; otherwise, the index date was defined as either the date of first observed HCV treatment or diagnosis date (if no treatment or liver transplant). Cox proportional hazards models were used to estimate the relative risk of liver transplant by level of treatment adherence ( $>80 \%, 50 \%-79 \%$, and $<50 \%$ ) based on proportion of days covered. General linearized models with log link and gamma distribution were used to compare median total health care costs from index date until end of study period (or death/disenrollment, whichever came first) between treated and untreated liver transplant patients. All costs were converted to 2013 U.S. dollars and reported as total costs per patient and per patient per month (PPPM) to account for varying follow-up periods.

RESULTS: Of the 53,423 patients identified with HCV, 10,377 met exclusion criteria, leaving 43,046 patients (primarily Caucasian, males, mean age of 58 years) in the initial cohort. Only $6.29 \%(n=2,708)$ of the total HCV cohort received HCV treatment, and less than $1 \%(n=366,0.8 \%)$ received a liver transplant. Although there were no significant differences in the risk of liver transplant by adherence level, there was an upwards trend in the rate of liver transplant as adherence worsened (> 80\%: $1.25 \%$; $50 \%-79 \%$ : $1.30 \%$; and $<50 \%: 1.99 \%$ ), and the average days to liver transplant was longer with higher adherence (>80\%: 683; 50\%-79\%: 623; <50\%: 454). Only $48(13.11 \%)$ patients who received a liver transplant were treated for HCV. Adjusted median total and PPPM health care costs measured from index date until end of the study period were significantly higher for patients who received HCV treatment compared with those who did not (total $=\$ 231,139$ vs. $\$ 86,167$, adjusted $P<0.001 ; P P P M=\$ 20,583$ vs. $\$ 5,778$, adjusted $P=0.008$ ), driven by HCV-related medical costs and total pharmacy costs.
CONCLUSIONS: Adherence with HCV regimens did not affect risk of liver transplant, underscoring the need for further evidence linking treatment adherence to future liver transplant risk. HCV-treated patients who required liver transplant incurred significantly higher health care costs than those without HCV treatment before liver transplant. Introduction of newer all-oral direct-acting antiviral regimens, with higher acquisition costs, will require further research to more accurately assess medication adherence and its relationship with transplantation, as well as with total health care costs.

\section{J Manag Care Spec Pharm. 2016;22(7):863-71}

Copyright $\odot 2016$, Academy of Managed Care Pharmacy. All rights reserved.

\section{What is already known about this subject}

Achieving a sustained virologic response plays an important role in reducing the risk of liver-related morbidity/mortality, all-cause mortality, and health care utilization and increasing patientreported quality of life.

Adherence to hepatitis $C$ regimens is essential to the therapeutic efficacy of hepatitis $\mathrm{C}$ virus (HCV) treatments.

\section{What this study adds}

This study evaluated administrative data from a national payer to examine the association between medication adherence and risk of liver transplant and the impact of HCV treatment on total costs of liver transplantation.

Adherence to HCV treatment with older direct-acting antivirals, ribavirin, and pegylated interferon did not impact the risk of liver transplant.

Total and per patient per month health care costs were significantly higher for liver transplant recipients who received HCV treatment before transplant than for liver transplant recipients without HCV treatment.

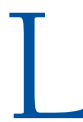

iver failure is a major health issue, resulting in over 700,000 deaths globally each year. ${ }^{1}$ In 2014, there were 5,723 single organ liver transplants in the United States, with average total per patient billed charges exceeding $\$ 739,000$. $^{2}$ Chronic hepatitis C virus (HCV) is the primary cause of liver failure leading to transplantation. ${ }^{1-4}$

Historically, standard therapy for $\mathrm{HCV}$ was pegylated interferon- $\alpha$ (PEG-IFN) injection combined with oral ribavirin (RBV), providing a sustained virologic response (SVR) of 


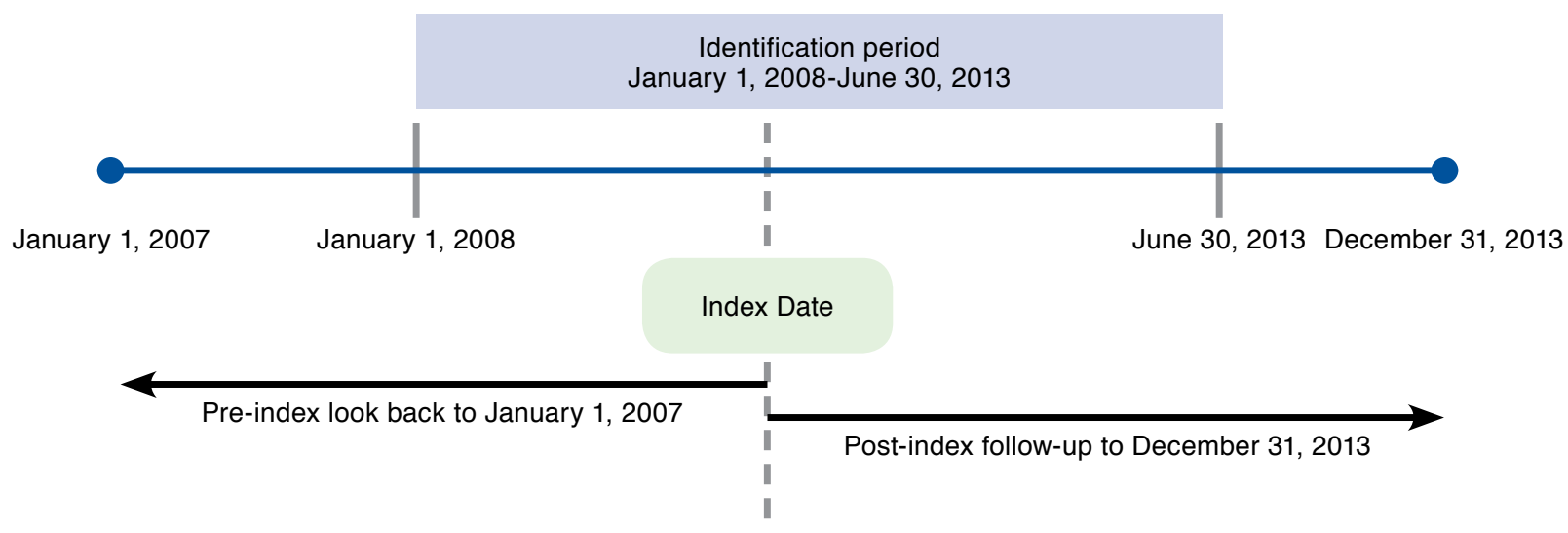

40\%-50\% after 48 weeks in genotype 1 patients. ${ }^{5}$ However, adverse events, most notably flu-like symptoms, depression, and anemia, and limited therapeutic efficacy frequently led to HCV treatment discontinuation or refusal. ${ }^{6-9}$ In 2011, when the first direct-acting antivirals (DAAs) telaprevir (TVR) and boceprevir (BOC) were approved by the U.S. Food and Drug Administration as add-on therapy with PEG-IFN and RBV, SVR rates in genotype 1 patients increased significantly to $60 \%-75 \%$. $^{5,10,11}$

The advent of newer DAAs (e.g., sofosbuvir, simeprevir, daclatasvir, ledipasvir, ombitasvir/paritaprevir/ritonavir combination, and dasabuvir) has further increased SVR rates in genotype 1 patients to $80 \%-90 \%$ with a shorter course of therapy, few monitoring requirements, and without the need to supplement with PEG-IFN. ${ }^{12-19}$ Achieving SVR has been shown to reduce the risk of liver-related morbidity/mortality, all-cause mortality, and health care utilization and increase patientreported quality of life. ${ }^{3,20-25}$ In a large, prospective study of HCV patients who failed IFN-only therapy, 20\% of those not achieving SVR with subsequent PEG-IFN plus RBV progressed to liver transplant or death from any cause compared with only $3 \%$ of those who achieved SVR. ${ }^{3}$

Medication adherence is essential to the therapeutic efficacy of HCV treatments. ${ }^{26}$ A study of U.S. veterans showed a $66 \%$ decrease $(P=0.04)$ in viral load among patients who were $\geq 85 \%$ adherent to PEG-IFN plus RBV compared with those $<85 \%$ adherent. ${ }^{27}$ Further, study of a managed care population found that $40 \%-60 \%$ of patients with HCV were nonadherent (medication possession ratio <0.8), had significantly higher inpatient medical costs suggesting disease progression, and had more related inpatient procedures such as liver transplant in the nonadherent group. ${ }^{28}$ Although these studies did not quantify reasons for nonadherence, surveys of people with
HCV have cited adverse events as a primary challenge to treatment adherence with older and non-DAA regimens. ${ }^{9,29}$ Adverse events contributed to discontinuation rates of $16.5 \%$ with PEG-IFN and RBV and 8\%-21\% with BOC/TVR. ${ }^{14,30-34}$ Although clinical trials report much lower discontinuation rates (1\%-2\%) with newer DAA regimens, the impact of other factors (e.g., cost) on discontinuation rates in real-world clinical practice are not well understood. ${ }^{12,13}$

Although there is evidence linking poor adherence with lower SVR and consequent increased health care utilization and cost, there is a gap in the published literature regarding the examination of the association between medication adherence and risk of liver transplant as an outcome. In addition, the impact of HCV treatment on total cost of liver transplantation is not well documented. Accordingly, the objectives of this study were to compare (a) the relative risk of liver transplant by adherence in patients treated for HCV and (b) the total health care costs in treated and untreated patients who require liver transplant.

\section{Methods}

\section{Data Source}

This observational, historical cohort study was conducted using pharmacy and medical claims and enrollment data from the Humana Research Database, which derives data from approximately 4.2 million members nationwide across commercial and Medicare Advantage plans. ${ }^{35}$ Pharmacy claims contain adjudication information for prescription medications. Medical claims include diagnostic and procedure codes for inpatient and outpatient encounters. Enrollment data contain information on demographics and coverage dates. The study qualified for expedited review and was approved by the Schulman Associates Institutional Review Board. 


\section{FIGURE 2 Sample Attrition}

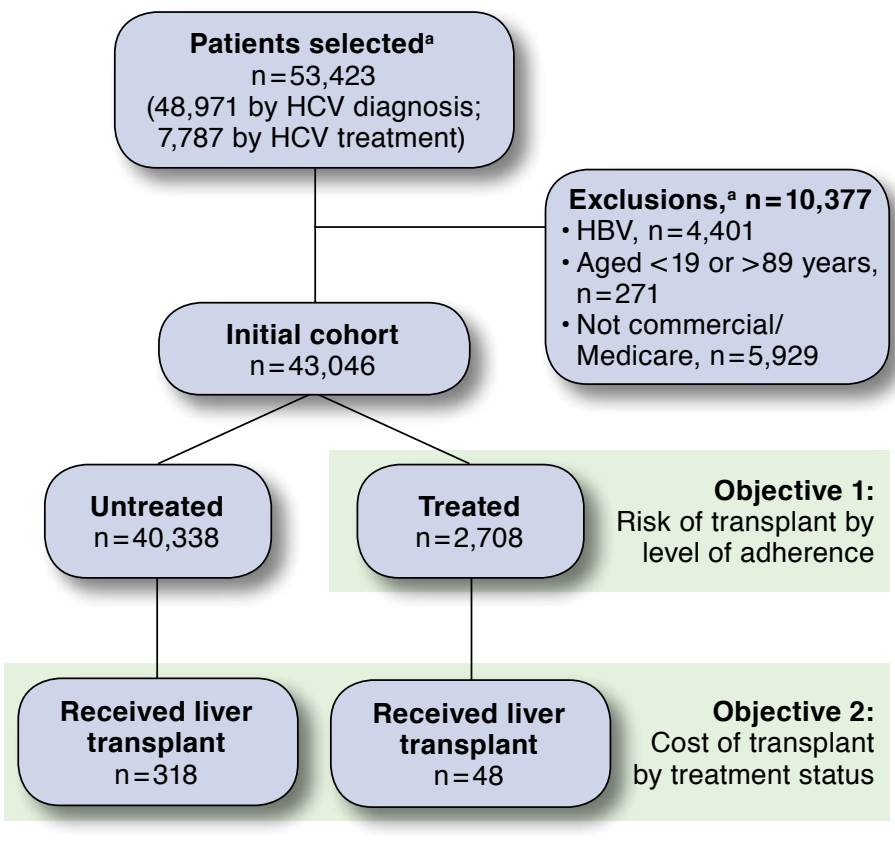

a Patients could have met more than 1 criterion.

$H B V=$ hepatitis $B$ virus; $H C V=$ hepatitis $C$ virus.

\section{Sample Selection}

Patients were initially selected for analysis if they had at least 1 International Classification of Diseases, Ninth Revision, Clinical Modification (ICD-9-CM) diagnosis consistent with HCV (codes V0262, 07041, 07044, 07051, 07054, 07070, and 07071); Current Procedural Terminology (CPT) category II or Healthcare Common Procedure Coding System (HCPCS) codes consistent with HCV (G8461, G8463, 4150F, and 4153F); or evidence of HCV treatment (boceprevir, telaprevir, ribavirin, PEG-IFN, or interferon alfacon-1, alone or in combination) between January 1, 2008, and June 30, 2013 (Figure 1). Newer DAAs (e.g., simeprevir, sofosbuvir, and ledipasvir) were not included because their market availability at a later period of this study prevented sufficient follow-up. Patients were excluded if they met any of the following criteria: diagnosis of hepatitis B virus (HBV; ICD-9-CM/CPT codes 070.20-070.23, 070.30-070.33, and V02.61); not fully insured by a commercial or Medicare Advantage Prescription Drug (MAPD) plan; or aged $<19$ or $>89$ years on their index date. For untreated patients who received liver transplantation, the study index date was defined as the date of liver transplant (ICD-9-CM codes 50.50, 50.51, 50.59; CPT codes 47135 and 47136); for all other patients, the index date was defined as either the date of first observed HCV treatment or diagnosis date (if not treated).
To maximize the sample size of patients at risk of liver transplant, a minimum pre- or post-index enrollment period was not required. Patients were followed for their entire post-index enrollment, through December 31, 2013, to capture evidence of $\mathrm{HCV}$ infection and liver transplantation and to assess for outcomes. The total sample was divided into treated and untreated groups and then subdivided by presence or absence of a liver transplant (Figure 2). This study investigated 2 main objectives. For objective 1, patients treated for HCV who received a liver transplant were evaluated to assess the potential impact of treatment adherence on future risk of liver transplant. For objective 2, treated and untreated patients who received a liver transplant were evaluated to assess differences in transplant costs between treated and untreated groups (Figure 2).

\section{Outcome Measures and Analyses}

Study cohorts were assessed for baseline demographic and clinical characteristics using Student's t-tests for continuous variables and chi square tests for categorical variables. For objective 1, Cox proportional hazards models were used to estimate the relative risk (RR) of liver transplant by level of treatment adherence. Untreated patients were not included in this comparison because of potential inherent differences in the population (e.g., less severe disease) owing to their untreated status. Three different adherence levels (> 80\%, 50\%-79\%, and $<50 \%$ ) were defined using proportion of days covered (PDC). PDC was calculated as the number of days covered by the index medication, based on fill dates and days supply for each HCV prescription refill, divided by the total days of treatment, based on the recommended treatment length for each HCV regimen. Only the index medication was used for calculating the PDC, regardless of the number of HCV therapies a patient may be receiving. Patients treated with only PEG-IFN and RBV in the 6 months immediately before the transplant, without other prescribed therapy before those 6 months, were considered untreated to avoid classifying a pretransplant regimen as HCV treatment. Patients who had a liver transplant or had been disenrolled were censored to maximize data capture during all available enrollment time. Adjusted analyses were conducted using age, gender, geographic location, Deyo-Charlson Comorbidity Index, Rx-Risk-V score, and pre-index medical and pharmacy costs as covariates.

For objective 2, general linearized models with log link and gamma distribution were used to compare median total costs (sum of plan and patient paid) of a liver transplant between treated and untreated patients. Total costs of care were measured from the index date until December 31, 2013, or death/ disenrollment, whichever came first, and were classified as HCV-related and non-HCV-related costs. All costs were converted to 2013 U.S. dollars and reported as total costs per patient, as well as per patient per month (PPPM) to account for varying follow-up periods. Presence of HCV diagnosis or 


\begin{tabular}{|c|c|c|c|c|c|c|c|c|c|c|}
\hline \multirow[b]{3}{*}{ Age, years, mean [SD] } & \multicolumn{5}{|c|}{ Patients with HCV } & \multicolumn{5}{|c|}{ Patients with HCV and Liver Transplant } \\
\hline & \multicolumn{2}{|c|}{$\begin{array}{l}\text { Untreated } \\
\mathrm{n}=40,338\end{array}$} & \multicolumn{2}{|c|}{$\begin{array}{c}\text { Treated } \\
\mathbf{n}=2,708\end{array}$} & \multirow{2}{*}{$\frac{P \text { Value }}{<0.001}$} & \multicolumn{2}{|c|}{$\begin{array}{l}\text { Untreated } \\
\mathrm{n}=318\end{array}$} & \multicolumn{2}{|c|}{$\begin{array}{c}\text { Treated } \\
\mathrm{n}=48\end{array}$} & \multirow{2}{*}{$\frac{P \text { Value }}{0.119}$} \\
\hline & 58.4 & {$[11.7]$} & 53.8 & {$[10.3]$} & & 57.0 & {$[7.5]$} & 55.2 & {$[6.3]$} & \\
\hline Male gender, $\mathrm{n}(\%)$ & 23,447 & $(58.1)$ & 1,723 & $(63.6)$ & $<0.001$ & 234 & $(73.6)$ & 35 & $(72.9)$ & 0.922 \\
\hline Race/ethnicity, n (\%)a & & & & & $<0.001$ & & & & & 0.421 \\
\hline Caucasian & 19,275 & $(65.0)$ & 1,124 & $(70.0)$ & - & 192 & $(78.4)$ & 20 & $(69.0)$ & - \\
\hline African American & 4,960 & $(16.7)$ & 267 & $(16.6)$ & - & 25 & $(10.2)$ & 5 & $(17.2)$ & - \\
\hline Hispanic & 713 & $(2.4)$ & 38 & $(2.4)$ & - & 6 & $(2.5)$ & 0 & $(0.0)$ & - \\
\hline Other/unknown & 4,699 & $(15.9)$ & 177 & $(11.0)$ & - & 22 & $(9.0)$ & 4 & $(13.8)$ & - \\
\hline Plan type, $\mathrm{n}(\%)$ & & & & & $<0.001$ & & & & & 0.013 \\
\hline Commercial & 10,691 & $(26.5)$ & 1,102 & $(40.7)$ & - & 73 & $(23.0)$ & 19 & $(39.6)$ & - \\
\hline MAPD & 29,647 & $(73.5)$ & 1,606 & $(59.3)$ & - & 245 & $(77.0)$ & 29 & $(60.4)$ & - \\
\hline Rx-Risk-V comorbidity score, mean [SD] & 5.0 & [3.1] & 4.3 & [2.9] & $<0.001$ & 4.7 & [4.0] & 3.1 & [3.4] & 0.007 \\
\hline Deyo-Charlson Comorbidity Index, mean [SD] & 1.0 & {$[2.0]$} & 0.7 & {$[1.9]$} & $<0.001$ & 2.8 & {$[3.3]$} & 1.8 & {$[2.7]$} & 0.048 \\
\hline \multicolumn{11}{|l|}{ HCV treatment, n (\%) } \\
\hline PEG-IFN + RBV & \multicolumn{2}{|c|}{-} & 1,369 & $(50.6)$ & - & \multicolumn{2}{|c|}{-} & 27 & $(56.0)$ & - \\
\hline Protease inhibitor + PEG-IFN + RBVb & \multicolumn{2}{|c|}{-} & 919 & $(33.9)$ & - & \multicolumn{2}{|c|}{-} & 16 & $(33.3)$ & - \\
\hline Intron A+RBV & \multicolumn{2}{|c|}{-} & 238 & $(8.8)$ & - & \multicolumn{2}{|c|}{-} & 0 & $(0.0)$ & - \\
\hline PEG-IFN monotherapy & \multicolumn{2}{|c|}{-} & 61 & $(2.3)$ & - & \multicolumn{2}{|c|}{ - } & 2 & $(4.2)$ & - \\
\hline Interferon alfacon-1 + RBV (as initial treatment) & \multicolumn{2}{|c|}{-} & 20 & $(0.7)$ & - & \multicolumn{2}{|c|}{-} & 0 & $(0.0)$ & - \\
\hline Otherc & \multicolumn{2}{|c|}{-} & 101 & $(3.7)$ & - & \multicolumn{2}{|c|}{-} & 3 & $(6.3)$ & - \\
\hline $\begin{array}{l}\text { Pre-index all-cause health care costs } \\
\text { (average monthly \$), mean [SD] }\end{array}$ & \multicolumn{2}{|c|}{$3,657 \quad[35,015]$} & 7,073 & {$[56,943]$} & $<0.001$ & \multicolumn{2}{|c|}{$18,156[141,411]$} & 7,823 & {$[21,392]$} & 0.614 \\
\hline Pre-index eligibility, months, mean [SD] & 11.9 & {$[18.0]$} & 9.7 & {$[16.2]$} & $<0.001$ & 13.4 & {$[20.4]$} & 9.5 & [19.9] & 0.217 \\
\hline Post-index eligibility, months, mean [SD] & 14.0 & {$[14.4]$} & 15.1 & {$[13.4]$} & $<0.001$ & 19.0 & {$[17.0]$} & 17.1 & {$[16.7]$} & 0.466 \\
\hline \multicolumn{11}{|l|}{ Indications for priority treatment, ${ }^{36} \mathrm{n}(\%)$} \\
\hline Renal failure & 1,162 & $(2.9)$ & 25 & $(0.9)$ & $<0.001$ & 20 & $(6.3)$ & 2 & $(4.2)$ & 0.564 \\
\hline Type 2 diabetes mellitus & 9,945 & $(24.7)$ & 418 & $(15.4)$ & $<0.001$ & 104 & $(32.7)$ & 13 & $(27.1)$ & 0.436 \\
\hline Liver failure & 378 & $(0.9)$ & 18 & $(0.7)$ & 0.150 & 20 & $(6.3)$ & 3 & $(6.3)$ & 0.992 \\
\hline HIV coinfection & 706 & (1.8) & 35 & (1.3) & 0.080 & 2 & $(0.6)$ & 0 & $(0.0)$ & 0.582 \\
\hline Porphyria cutanea tarda & 77 & $(0.2)$ & 8 & $(0.3)$ & 0.230 & 0 & $(0.0)$ & 1 & $(2.1)$ & 0.010 \\
\hline $\begin{array}{l}\text { Proteinuria, nephrotic syndrome, or } \\
\text { membranoproliferative glomerulonephritis }\end{array}$ & 1,137 & $(2.8)$ & 36 & (1.3) & $<0.001$ & 11 & $(3.5)$ & 3 & $(6.3)$ & 0.348 \\
\hline $\begin{array}{l}\text { Type } 2 \text { or } 3 \text { essential mixed cryoglobulinemia } \\
\text { with end organ manifestations (e.g., vasculitis) }\end{array}$ & & $(0.1)$ & 3 & $(0.1)$ & 0.510 & 0 & $(0.0)$ & 0 & $(0.0)$ & - \\
\hline \multicolumn{11}{|c|}{ 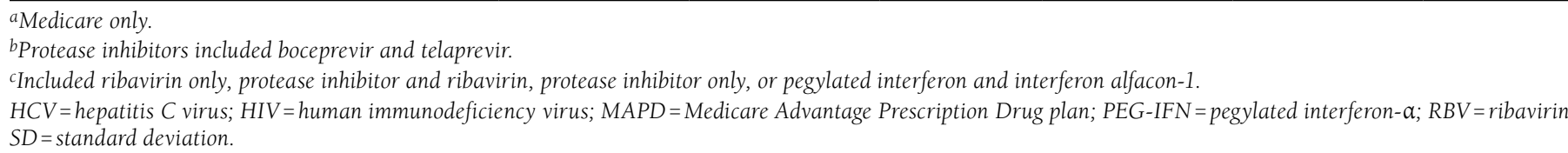 } \\
\hline
\end{tabular}

procedure codes, HCV treatment, or a history of liver dysfunction in the claims data during the study period were used to identify costs as HCV-related. Adjusted analyses were also conducted using the same covariates noted for objective 1 .

All analyses were conducted using SAS Enterprise Guide 5.1 (SAS Institute, Cary, NC) with an a priori alpha level for all inferential analyses set at 0.05 .

\section{Results}

Between January 1, 2008, and June 30, 2013, 53,423 patients with HCV infection were identified $(n=7,787$ identified by prescriptions for HCV treatment; $\mathrm{n}=48,971$ identified by at least $1 \mathrm{HCV}$ diagnosis; some patients met both criteria). After excluding 10,377 patients who met exclusion criteria (HBV coinfection, aged $<19$ or $>89$ years, not fully insured by commercial or Medicare), 43,046 patients remained in the initial $\mathrm{HCV}$ cohort (Figure 2). The study population was primarily Caucasian (65\%-78\%) males (58\%-73\%) with MAPD insurance and a mean age of 58 years (Table 1). A higher percentage of untreated patients were diagnosed with diabetes, renal failure, and human immunodeficiency virus coinfection, which are all complications used in prioritizing treatment based on the HCV guidelines. ${ }^{36}$ The Charlson Comorbidity Index was higher in untreated transplant recipients. Only $6.29 \%(n=2,708)$ of the 


\begin{tabular}{|c|c|c|c|c|}
\hline Adherence Level & Total & $\begin{array}{c}\text { Liver } \\
\text { Transplant, } \\
\text { n (\%) }\end{array}$ & $\begin{array}{c}\text { RR of Liver } \\
\text { Transplant } \\
\text { (95\% CI) }\end{array}$ & $\begin{array}{c}P \text { Value } \\
\text { Adjusted }\end{array}$ \\
\hline Adherent ( $\geq 80 \%)$ & 460 & $6 \quad(1.3)$ & Reference & - \\
\hline Low (50\%-79\%) & 386 & $5(1.3)$ & $0.9(0.6-3.3)$ & 0.636 \\
\hline Very low $(<50 \%)$ & 1,862 & $37(2.0)$ & $1.7(0.5-2.7)$ & 0.208 \\
\hline Total & 2,708 & $48 \quad(1.8)$ & - & - \\
\hline
\end{tabular}

total HCV cohort received HCV treatment, and less than $1 \%$ $(\mathrm{n}=366)$ received a liver transplant. A higher percentage of treated than untreated patients in the overall cohort received a liver transplant ( $1.8 \%$ and $0.8 \%$, respectively).

\section{Objective 1: Relative Risk of Liver Transplant}

The absolute rate of liver transplant trended upwards as adherence worsened $(1.25 \%, 1.30 \%$, and $1.99 \%$ for high, low, and very low adherence levels, respectively) but did not meet statistical significance based on $P$ values $>0.05$ (Table 2). Similarly, the average time to liver transplant was longer with higher adherence ( 683 days, 623 days, and 454 days for high, low, and very low adherence levels, respectively; Figure 3). The RR of liver transplant for low (PDC 50\%-79\%, RR=0.9) and very low (PDC $<50 \%, \mathrm{RR}=1.7)$ adherence levels was not significantly different from patients who were highly adherent (PDC $>80 \%$, $R R=1.0$, reference group) for each respective course of treatment (Table 2).

\section{Objective 2: Total Costs of Liver Transplant by Treatment Status}

Of the 366 patients who received a liver transplant during the study period, only 48 (13.11\%) were treated for HCV. Similar to findings in the larger sample, the majority of liver transplant patients who received HCV treatment before the transplant were nonadherent with therapy $(87.5 \%$ with $\mathrm{PDC}<80 \%)$. Adjusted and unadjusted analyses found total median health care costs significantly higher for patients who received HCV treatment than for those who did not $(\$ 231,139$ vs. $\$ 86,167$ respectively, $P=0.001$, adjusted $P<0.001$; Table 3). Significant differences were also found in adjusted median PPPM costs ( $\$ 20,583$ treated vs. $\$ 5,778$ untreated, $P=0.076$, adjusted $P=0.008$ ), which account for variations in patient follow-up time between treated and nontreated liver transplant patients. Higher HCV-related median medical costs in the treated cohort drove the significant differences between groups, but median non-HCV medical costs did not differ. Unadjusted and adjusted median pharmacy costs were significantly higher in the treated liver transplant population, driven by HCV-related medication (total: $\$ 20,034$ treated vs. $\$ 0$ untreated; PPPM: $\$ 4,134$ treated vs. $\$ 817$ untreated, adjusted $P<0.001$ ) and non-HCV medication costs (total: $\$ 22,473$ treated vs. $\$ 12,604$ untreated, adjusted $P<0.001$; PPPM: $\$ 1,824$ treated vs. $\$ 817$ untreated, adjusted $P=0.04$ ).

\section{Discussion}

This study was initiated to better understand the relationship between HCV treatment and clinical outcomes and hence inform projections as newer DAAs become available. This study assessed medications that are no longer standard of care because, as treatment paradigms shift to newer options, health plans remain reliant on available data, which are frequently limited by new product uptake, lags in claims processing, and length of time required to measure long-term outcomes. These findings represent real-world evidence that provides insight into the relationship between HCV treatment and outcomes but also raises questions beyond the scope of claims data analysis.

First, we found that more people who received HCV treatment went on to receive a liver transplant (1.8\%) compared with those who were not treated $(0.8 \%)$, which may indicate that patients with advanced liver disease are more likely to receive HCV treatment. However, baseline comorbidities used to prioritize treatment were similar between groups, and claims-based comorbidity scores suggest that the untreated group was actually sicker at baseline. This finding suggests that there are unmeasured complexities influencing treatment and transplant decisions that likely affected the findings of this study. Second, we found that the likelihood of transplant among HCV-treated patients was not affected by treatment adherence, which is counterintuitive based on the established correlation between adherence and SVR in the literature. ${ }^{27}$ Replicating this study with newer agents, which have demonstrated greater improvements in SVR, will help determine whether such findings persist. Finally, we found that among transplanted patients, PPPM and total costs were higher for those who received treatment versus untreated, supporting the notion that there are variables not available in claims data that influence treatment and transplant decisions. Nonetheless, such data are useful as health plans project future costs related to HCV and how those costs may change with screening recommendations and changes in treatment market share.

This is the first published study attempting to link HCV medication adherence to the long-term outcome of liver transplant. Unexpectedly, our results suggest that liver transplant risk is not affected by greater treatment adherence. However, interpretation of these results must take into consideration certain factors, since the liver transplantation decision is complex and incorporates many variables, such as disease severity and social factors affecting transplant eligibility, that could not be assessed in this analysis. Demonstrated poor adherence to HCV medication regimens may also preclude individuals from transplantation eligibility, which adds a potential bias to our 


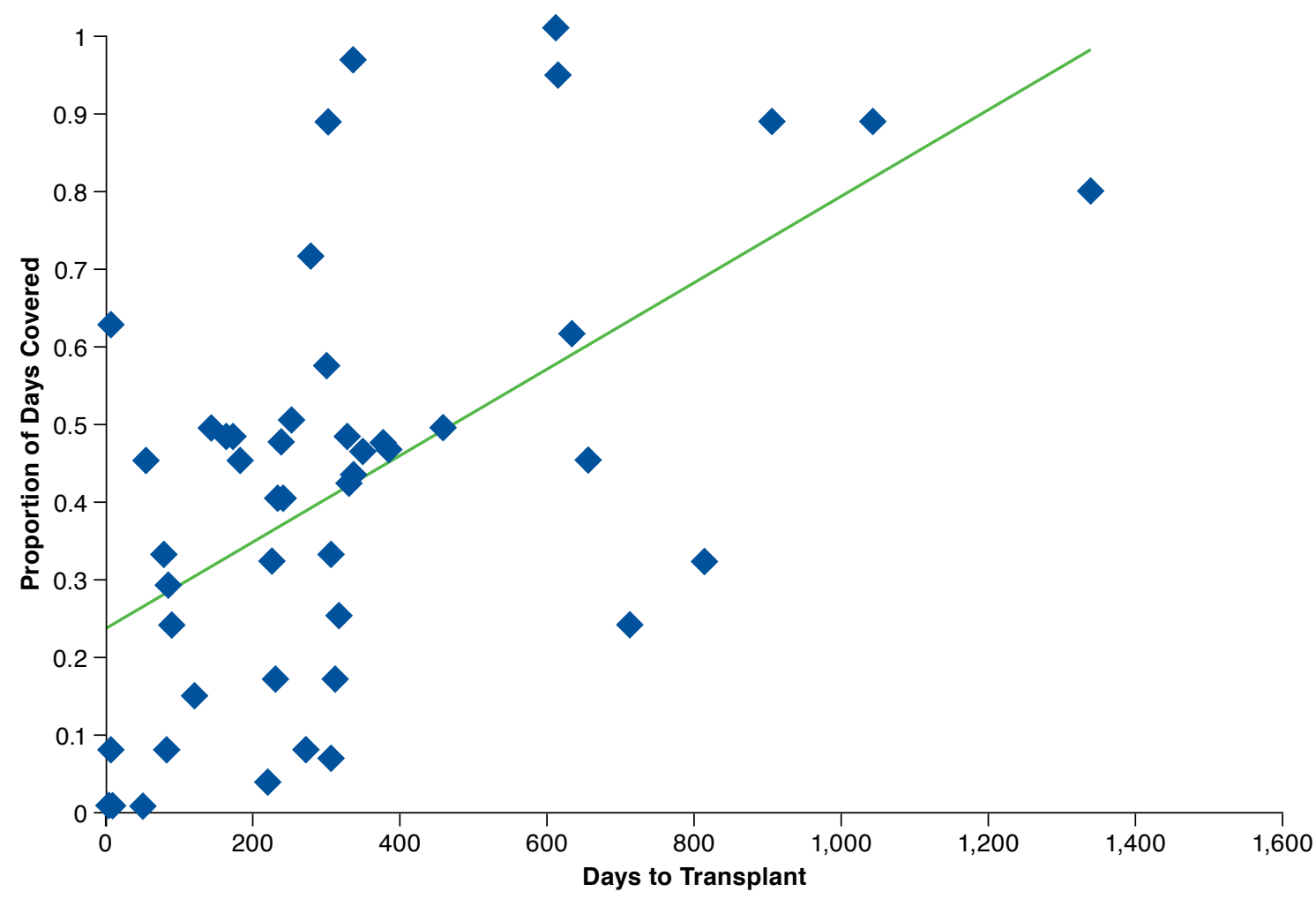

HCV = hepatitis $C$ virus.

results. ${ }^{36}$ Additionally, the limited number of available donor organs and strict clinical eligibility requirements for transplantation make liver transplants a rare event, with less than $1 \%$ of this study population receiving transplants. Thus, the ability to detect statistical differences is limited, even with such a large study population. Accordingly, although the low adherence group had an increased risk of transplant $(R R=1.7)$ compared with the adherent group, there was no significant difference between the 2 groups. While this study provides initial insight into the relationship between adherence and liver transplant, additional research is needed to explore the influence of other factors not readily available in claims data but which may have significant bearing on the risk of liver transplantation.

Adherence in this study was generally lower than that of other studies, with nearly $70 \%$ of the population being less than 50\% adherent. Veterans treated with PEG-IFN and RBV achieved $\geq 85 \%$ adherence ( $95 \%$ and $88 \%$, respectively) over 12 weeks. ${ }^{27}$ A prospective HCV study reported less than $10 \%$ missed PEG-IFN doses, 15\%-25\% missed RBV doses, and 90\% persistence for both treatments over a year. ${ }^{30}$ Two claims analyses described lower adherence, albeit still higher than results from the current study. Medication possession ratios $\geq 0.8$ (adherent) were noted in 60\% of patients receiving PEG-IFN with RBV, $46 \%$ on PEG-IFN alone, and only $36 \%$ of patients taking nonpegylated IFN plus RBV in 1 study; another analysis reported incomplete therapy rates of $74 \%$ for BOC and 54\% for TVR. ${ }^{28,37}$ Several factors may explain these differences, including differing definitions and calculations for adherence, varied follow-up periods, and greater clinical oversight associated with prospective studies and the Veterans Affairs health care program. Treatment discontinuation rates for newer DAAs appear to be much lower (1\%-2\%) than older therapies, possibly because of better tolerability and oral dosing. However, adherence to these newer options has only been assessed in clinical trials, and data from real-world clinical practice are needed to corroborate these findings. ${ }^{12,13}$ Additionally, the present study did not measure disease severity or treatment response, both of which influence the decision to continue treatment. There are many other factors beyond drug tolerability, such as comorbid depression, poor access to health care, limited or no insurance coverage, and drug and alcohol abuse, which can negatively impact HCV medication adherence. ${ }^{38-41}$ The complexity of successful long-term management of chronic HCV and results of 


\begin{tabular}{|c|c|c|c|c|}
\hline \multirow[t]{3}{*}{ TABLE 3} & \multicolumn{4}{|c|}{$\begin{array}{l}\text { Cost Differences Between HCV Treated } \\
\text { and Untreated Patients Who Received } \\
\text { Liver Transplant }\end{array}$} \\
\hline & $\begin{array}{c}\text { Transplant, } \\
\text { Untreated } \\
\mathbf{n}=318\end{array}$ & $\begin{array}{c}\text { Transplant, } \\
\text { Treated } \\
\mathbf{n}=48\end{array}$ & \multicolumn{2}{|c|}{$P$ Value } \\
\hline & Median & Median & Unadjusted & Adjusted \\
\hline $\begin{array}{l}\text { Total health } \\
\text { care costs }\end{array}$ & $\$ 86,167$ & $\$ 231,139$ & 0.001 & $<0.001$ \\
\hline Medical & $\$ 64,062$ & $\$ 134,717$ & 0.096 & 0.034 \\
\hline HCV related & $\$ 31,546$ & $\$ 100,455$ & 0.036 & 0.025 \\
\hline Non-HCV related & $\$ 17,934$ & $\$ 17,802$ & 0.914 & 0.829 \\
\hline Pharmacy & $\$ 12,604$ & $\$ 62,553$ & $<0.001$ & $<0.001$ \\
\hline $\begin{array}{l}\text { Index (lst) HCV } \\
\text { medications }\end{array}$ & NA & $\$ 20,034$ & - & - \\
\hline $\begin{array}{l}\text { Non-index (2nd) } \\
\text { HCV medications }\end{array}$ & NA & - & - & - \\
\hline $\begin{array}{l}\text { Non-index, non- } \\
\text { HCV medications }\end{array}$ & $\$ 12,604$ & $\$ 22,473$ & 0.002 & $<0.001$ \\
\hline $\begin{array}{l}\text { PPPM health } \\
\text { care costs }\end{array}$ & $\$ 5,778$ & $\$ 20,583$ & 0.076 & 0.008 \\
\hline Medical & $\$ 4,308$ & $\$ 11,170$ & 0.457 & 0.156 \\
\hline HCV related & $\$ 2,304$ & $\$ 8,493$ & 0.048 & 0.017 \\
\hline Non-HCV related & $\$ 1,307$ & $\$ 1,250$ & 0.177 & 0.278 \\
\hline Pharmacy & $\$ 817$ & $\$ 4,134$ & $<0.001$ & $<0.001$ \\
\hline $\begin{array}{l}\text { Index (lst) HCV } \\
\text { product }\end{array}$ & NA & $\$ 1,489$ & - & - \\
\hline $\begin{array}{l}\text { Non-index (2nd) } \\
\text { HCV product }\end{array}$ & NA & - & - & - \\
\hline $\begin{array}{l}\text { Non-index, } \\
\text { non-HCV product }\end{array}$ & $\$ 817$ & $\$ 1,824$ & 0.088 & 0.040 \\
\hline
\end{tabular}

the current study underscore the need to consider medication adherence in the context of other variables.

Transplant recipients who had HCV treatment incurred significantly higher median total and PPPM costs compared with those without treatment, despite higher baseline comorbidity scores in the untreated group. While differences in index date definitions (date of HCV treatment initiation in treated patients vs. date of liver transplant in untreated patients) may have biased results toward higher median total costs in the treated population, analysis of median PPPM costs, which were also significantly higher in treated patients, should have normalized any differences in follow-up time between the 2 groups. In addition, treated and untreated patients had similar pre- and post-index eligibility. Since the present study did not assess liver disease severity (e.g., cirrhosis, liver fibrosis, and previous $\mathrm{HCV}$ treatment response), it is possible that treated patients could have had more progressive disease despite similar rates of liver failure at baseline (6.3\% in both groups). If patients with progressive disease are more likely to be treated, this could confound differences in total and HCV-related costs. Cost differences were driven by higher adjusted median HCV-related medical costs and total pharmacy costs (HCV-related and nonHCV-related). While this finding is not altogether surprising given the high and increasing price of HCV therapies, adjusted median non-HCV-related medical costs were similar in treated and untreated groups. Finally, since medication nonadherence is associated with excessive costs in other chronic diseases, the high rate of medication nonadherence in this study could have contributed to cost differences. Future research is needed to understand if higher HCV-related medical costs and nonHCV-related pharmacy costs represent treatment of adverse events-costs that could diminish with newer DAAs.

Before progressing to liver transplant, declining health status (e.g., bleeding, portal hypertension, and hepatic encephalopathy), increased health care utilization, and decreased patient productivity present a large burden in terms of medical costs and societal impact. Although liver transplant costs are high, downstream improvements in health and quality of life can offset initial costs. Follow-up time in this study (a year and a half on average) may not have been sufficient to capture longer-term health benefits and quality of life improvements post-transplantation, which are frequently part of cost-effectiveness analyses.

\section{Limitations}

This study was subject to certain limitations. Several variables were not available in the claims source, including treatment response (e.g., SVR), transplant eligibility requirements, reasons for nonadherence, and actual medication consumption. These unmeasured variables may have affected the outcomes, although they would theoretically affect all groups equally. Furthermore, the effect of social determinants of health, such as education and employment levels and access to housing and health care, are typically absent from claims data and could not be assessed. No statistical adjustments were made to address the large difference in sample size between comparison groups. The generalizability of the study is limited in that the study population was from a single health plan. However, the population was sizable enough to identify 366 persons with liver transplant, allowing for evaluation of that endpoint. In an attempt to maximize the sample size, variable post-index periods were allowed, introducing potential bias toward those with longer follow-up periods. This approach increases the likelihood of confounding but also produces findings that are reflective of actual observed outcomes of the population. Importantly, the study time period excluded the newer DAA agents that have been approved since June 2013 because there was insufficient longitudinal data available to analyze the newer DAA agents. A follow-up study is needed to determine if newer, all-oral DAA regimens, with potentially greater adherence and therapy completion rates, would have a different effect on transplant risk or costs. 


\section{Conclusions}

In this population, higher HCV treatment adherence with BOC, TVR, RBV, and PEG-IFN (alone or in combination) for HCV did not translate into a decreased risk of liver transplant, underscoring the need for further evidence linking treatment adherence to future liver transplant risk. HCV-treated patients who went on to require a liver transplant incurred significantly higher total and PPPM health care costs than those who did not receive HCV treatment before transplant. Introduction of newer all-oral DAA regimens, with higher acquisition costs, will require further research to more accurately assess medication adherence and its relationship with transplantation, as well as total health care costs.

\section{Authors}

DEREK EMS, MPH; PATRICK RACSA, MS; KAREN WORLEY, PhD; and WORTHE HOLT, MD, Comprehensive Health Insights, Humana, Louisville, Kentucky. CHRIS ANDERSON, PharmD, and FRAN GREGORY, PharmD, Humana, Louisville, Kentucky. JOEL V. BRILL, MD, Predictive Health, Paradise Valley, Arizona.

AUTHOR CORRESPONDENCE: Derek Ems, MPH, Comprehensive Health Insights, 515 W. Market St., Louisville, KY 40202.

Tel.: 502.476.8891; E-mail: dems1@humana.com.

\section{DISCLOSURES}

No outside funding supported this research. Ems, Worley, Racsa, Gregory, Anderson, and Holt are employees of Humana. Brill has participated in a physician advisory board at Humana. The authors have no other financial disclosures to report.

Study concept and design were contributed by Ems, Racsa, Worley, and Anderson, along with Gregory, Brill, and Holt. Racsa took the lead in data collection, along with Ems and Worley. All authors participated in data interpretation. Anderson, along with the other authors, wrote the manuscript, which was revised by Brill and Holt, with assistance from the other authors.

\section{ACKNOWLEDGMENTS}

The authors thank Charron Long for her contributions to the writing of this manuscript.

\section{REFERENCES}

1. Vilarinho S, Lifton RP. Liver transplantation: from inception to clinical practice. Cell. 2012;150(6):1096-99.

2. Bentley TS. 2014 U.S. organ and tissue transplant cost estimates and discussion. Milliman Research Report. December 2014. Available at: http://www.milliman.com/uploadedFiles/insight/Research/healthrr/1938HDP_20141230.pdf. Accessed May 10, 2016.

3. Manos MM, Darbinian J, Rubin J, et al. The effect of hepatitis $C$ treatment response on medical costs: a longitudinal analysis in an integrated care setting. J Manag Care Pharm. 2013;19(6):438-47. Available at: http://www.jmcp. org/doi/abs/10.18553/jmcp.2013.19.6.438.
4. Organ Procurement and Transplantation Network (OPTN) and Scientific Registry of Transplant Recipients (SRTR). OPTN/SRTR 2010 annual data report. Rockville, MD: Department of Health and Human Services, Health Resources and Services Administration, Healthcare Systems Bureau, Division of Transplantation; 2011. Available at: http://srtr.transplant.hrsa. gov/annual_reports/2010/pdf/2010_srtr_adr.pdf. Accessed May 10, 2016.

5. Ghany MG, Nelson DR, Strader DB, Thomas DL, Seeff LB; American Association for Study of Liver Diseases. An update on treatment of genotype 1 chronic hepatitis $C$ virus infection: 2011 practice guideline by the American Association for the Study of Liver Diseases. Hepatology. 2011;54(4):1433-44.

6. Martel-Laferrière V, Bichoupan K, Dieterich DT. Interferon-free regimens for hepatitis C: combine and conquer. BioDrugs. 2014;28(2):161-69.

7. Poordad F, Chee GM. Interferon free hepatitis $C$ treatment regimens: the beginning of another era. Curr Gastroenterol Rep. 2012;14(1):74-77.

8. Fusfeld L, Aggarwal J, Dougher C, et al. Assessment of motivating factors associated with the initiation and completion of treatment for chronic hepatitis C virus (HCV) infection. BMC Infect Dis. 2013;13:234.

9. McNally S, Temple-Smith M, Sievert W, Pitts MK. Now, later or never? Challenges associated with hepatitis C treatment. Aust N Z J Public Health. 2006;30(5):422-27.

10. Kanda T, Yokosuka O, Omata M. Treatment of hepatitis C virus infection in the future. Clin Transl Med. 2013;2(1):9.

11. Cooper C, Lester R, Thorlund K, et al. Direct-acting antiviral therapies for hepatitis $C$ genotype 1 infection: a multiple treatment comparison metaanalysis. QJM. 2013;106(2):153-63.

12. Lawitz E, Mangia A, Wyles D, et al. Sofosbuvir for previously untreated chronic hepatitis C infection. N Engl J Med. 2013;368(20):1878-87.

13. Jacobson IM, Dore GJ, Foster GR, et al. Simeprevir with pegylated interferon alfa 2 a plus ribavirin in treatment-naive patients with chronic hepatitis C virus genotype 1 infection (QUEST-1): a phase 3, randomised, doubleblind, placebo-controlled trial. Lancet. 2014;384(9941):403-13.

14. Zeuzem S, Andreone P, Pol S, et al; REALIZE Study Team. Telaprevir for retreatment of HCV infection. N Engl J Med. 2011;364(25):2417-28.

15. Manns M, Marcellin P, Poordad F, et al. Simeprevir with pegylated interferon alfa $2 \mathrm{a}$ or $2 \mathrm{~b}$ plus ribavirin in treatment-naive patients with chronic hepatitis $C$ virus genotype 1 infection (QUEST-2): a randomised, doubleblind, placebo-controlled phase 3 trial. Lancet. 2014;384(9941):414-26.

16. Forns X, Lawitz E, Zeuzem S, et al. Simeprevir with peginterferon and ribavirin leads to high rates of SVR in patients with HCV genotype 1 who relapsed after previous therapy: a phase 3 trial. Gastroenterology. 2014;146(7):1669-79.e3.

17. Afdhal N, Zeuzem S, Kwo P, et al; ION-1 Investigators. Ledipasvir and sofosbuvir for untreated HCV genotype 1 infection. N Engl J Med. 2014;370(20):1889-98.

18. Afdhal N, Reddy KR, Nelson DR, et al; ION-2 Investigators. Ledipasvir and sofosbuvir for previously treated HCV genotype 1 infection. N Engl J Med. 2014;370(16):1483-93.

19. Kowdley KV, Gordon SC, Reddy KR, et al; ION-3 Investigators. Ledipasvir and sofosbuvir for 8 or 12 weeks for chronic HCV without cirrhosis. N Engl J Med. 2014;370(20):1879-88.

20. Morgan TR, Ghany MG, Kim HY, et al; HALT-C Trial Group. Outcome of sustained virological responders with histologically advanced chronic hepatitis C. Hepatology. 2010;52(3):833-44.

21. Singal AG, Volk ML, Jensen D, Di Bisceglie AM, Schoenfeld PS. A sustained viral response is associated with reduced liver-related morbidity and mortality in patients with hepatitis C virus. Clin Gastroenterol Hepatol. 2010;8(3):280-88.el.

22. Backus LI, Boothroyd DB, Phillips BR, Belperio P, Halloran J, Mole LA. A sustained virologic response reduces risk of all-cause mortality in patients with hepatitis C. Clin Gastroenterol Hepatol. 2011;9(6):509-16.e1. 
23. Bonkovsky HL, Snow KK, Malet PF, et al; HALT-C Trial Group. Healthrelated quality of life in patients with chronic hepatitis $C$ and advanced fibrosis. J Hepatol. 2007;46(3):420-31.

24. John-Baptiste AA, Tomlinson G, Hsu PC, et al. Sustained responders have better quality of life and productivity compared with treatment failures long after antiviral therapy for hepatitis C. Am J Gastroenterol. 2009;104(10):2439-48

25. Younossi ZM, Singer ME, Mir HM, Henry L, Hunt S. Impact of interferon free regimens on clinical and cost outcomes for chronic hepatitis $C$ genotype 1 patients. J Hepatol. 2014;60(3):530-37.

26. Owens GM. Revolutionizing treatment outcomes in hepatitis C: managed care implications and considerations-the new and evolving standards of care. Am J Manag Care. 2015;21(5 Suppl):s97-s105.

27. Lo Re V 3rd, Amorosa VK, Localio AR, et al. Adherence to hepatitis C virus therapy and early virologic outcomes. Clin Infect Dis. 2009;48(2):186-93.

28. Mitra D, Davis KL, Beam C, Medjedovic J, Rustgi V. Treatment patterns and adherence among patients with chronic hepatitis $C$ virus in a US managed care population. Value Health. 2010;13(4):479-86.

29. Brett Hauber A, Mohamed AF, Beam C, Medjedovic J, Mauskopf J. Patient preferences and assessment of likely adherence to hepatitis $C$ virus treatment. J Viral Hepat. 2011;18(9):619-27.

30. Evon DM, Esserman DA, Bonner JE, Rao T, Fried MW, Golin CE. Adherence to PEG/ribavirin treatment for chronic hepatitis C: prevalence, patterns, and predictors of missed doses and nonpersistence. J Viral Hepat. 2013;20(8):536-49.

31. McHutchison JG, Everson GT, Gordon SC, et al; PROVEl Study Team. Telaprevir with peginterferon and ribavirin for chronic HCV genotype 1 infection. N Engl J Med. 2009;360(18):1827-38.

32. Jacobson IM, McHutchison JG, Dusheiko G, et al; ADVANCE Study Team. Telaprevir for previously untreated chronic hepatitis $C$ virus infection. N Engl J Med. 2011;364(25):2405-16.
33. Bacon BR, Gordon SC, Lawitz E, et al; HCV RESPOND-2 Investigators. Boceprevir for previously treated chronic HCV genotype 1 infection. N Engl J Med. 2011;364(13):1207-17.

34. Poordad F, McCone J Jr, Bacon BR, et al; SPRINT-2 Investigators. Boceprevir for untreated chronic HCV genotype 1 infection. N Engl J Med. 2011;364(13):1195-206.

35. Humana. News release. Humana reports fourth quarter and full year 2013 financial results; reaffirms 2014 financial guidance. February 5, 2014. Available at: http://phx.corporate-ir.net/phoenix.zhtml?c=92913\&p=irolnewsArticle \&ID=1896989. Accessed May 10, 2016.

36. American Association for the Study of Liver Diseases; Infectious Diseases Society of America. HCV testing and linkage to care. Recommendations for testing, managing, and treating hepatitis C. Available at: http://www.hcvguidelines.org/full-report/hcv-testing-and-linkage-care. Accessed May 10, 2016

37. Le TK, Kalsekar A, Macaulay D, et al. Treatment patterns, health care resource utilization, and costs in U.S. patients diagnosed with chronic hepatitis $C$ infection who received telaprevir or boceprevir. J Manag Care Spec Pharm. 2015;21(4):308-18. Available at: http://www.jmcp.org/doi/ abs/10.18553/jmcp.2015.21.4.308.

38. Lieveld FI, van Vlerken LG, Siersema PD, van Erpecum KJ. Patient adherence to antiviral treatment for chronic hepatitis B and C: a systematic review. Ann Hepatol. 2013;12(3):380-91.

39. Beste LA, Ioannou GN, Larson MS, Chapko M, Dominitz JA. Predictors of early treatment discontinuation among patients with genotype 1 hepatitis C and implications for viral eradication. Clin Gastroenterol Hepatol. 2010;8(11):972-78.

40. Butt AA, Mcginnis KA, Skanderson M, Justice AC. Hepatitis C treatment completion rates in routine clinical care. Liver Int. 2010;30(2):240-50.

41. Bonner JE, Esserman DA, Golin CE, Evon DM. Self-efficacy and adherence to antiviral treatment for chronic hepatitis C. J Clin Gastroenterol. 2015;49(1):76-83. 